Qingxian A., Z. Wang, A. Emrouznejad, Q. Zhu \& X. Chen (2018): Efficiency evaluation of parallel interdependent processes systems: an application to Chinese 985 Project universities, International Journal of Production Research. https://doi.org/10.1080/00207543.2018.1521531.

\title{
Efficiency evaluation of parallel interdependent processes systems: application to Chinese 985 Project universities
}

\author{
Qingxian An ${ }^{\mathrm{a}}$,Zongrun Wang ${ }^{\mathrm{a}}$, Ali Emrouznejad ${ }^{\mathrm{b}}$, Qingyuan Zhu ${ }^{\mathrm{c}} \& \mathrm{Xiaohong} \mathrm{Chen}^{\mathrm{a}, \mathrm{d}}$ \\ ${ }^{a}$ School of Business, Central South University, Changsha, People's Republic of China; \\ ${ }^{b}$ Aston Business School, Aston University, Birmingham, UK; \\ ${ }^{c}$ School of management, University of Science and Technology of China, Hefei, People's Republic of China; \\ ${ }^{d}$ Institute of Big Data and Internet Innovation, Hunan University of Commerce, Changsha, People's Republic of China
}

\begin{abstract}
Data envelopment analysis (DEA) has been widely applied in measuring the efficiency of homogeneous decision-making units. Network DEA, as an important branch of DEA, was built to examine the internal structure of a system, whereas traditional DEA models regard a system as a "black box". However, only a few previous studies on parallel systems has considered the interdependent relationship between system components. In recent years, parallel interdependent processes systems commonly exist in production systems because of serious competition among organizations. Thus, an approach to measure the efficiency of such systems should be proposed. This paper builds an additive DEA model to measure a parallel interdependent processes system with two components which have an interdependent relationship. Then, the model is applied to analyse the "985 Project" universities in China, and certain policy implications are explained.
\end{abstract}

Keywords: data envelopment analysis, parallel interdependent processes systems, network DEA, additive model, '985 Project' universities. 


\section{Introduction}

With the increasingly fierce competition, many production systems are becoming more complex than before to ensure operation efficiency, thereby lowering costs and improving competitiveness. The structure of a production system is no longer a mere chain but a network in which the relationship between two entities is generally not unidirectional but interdependent due to the development of information technology and transformation. In such a production system, one component provides some of its outputs to several other components, who also offer some of their outputs for the former component. For example, in a large organisation, each department in the system is connected with others by providing or consuming products or services. In 2007, the information transmission, computer services and software industry of China provided the financial industry with products and services worth approximately 4943.905 million RMB. The financial industry simultaneously offered the information transmission, computer services and software industry with products and services worth approximately 1388.203 million RMB. Another example is outsourcing. To maintain core competitiveness, a company may outsource its non-core business to an external company whilst the former company provides the external company financial or material support. In return, the external company supplies the corresponding products or services to the outsourcing company. This mutual activity can help a company use the external resources for its internal production and management services and consequently improve its performance. A company or even an industry must improve its performance to adapt to strong market competition. Measuring the performance (efficiency) of the system is important to realising this goal.

Data envelopment analysis (DEA) is a linear programming technique for measuring the relative efficiency of a set of homogeneous decision-making units (DMUs), especially with multiple inputs and outputs (Charnes et al. 1978). DEA has been applied to many areas, such as banks, hospitals and schools (Cook and Seiford 2009; Cooper et al. 2011; Kao 2009a; Wu et al. 2016a; Li et al. 2017; Lozano et al. 2017). Traditional DEA models, such as CCR model and BCC model, treat DMUs' 
internal structure as a "black box". To investigate internal structure systems and evaluate the relative efficiency of network systems, several network DEA models have been proposed, including serial and parallel systems, especially two-stage systems in which the outputs from the first stage are utilised as inputs for the second stage to produce the final outputs.

The independent two-stage DEA approach is a classic method of evaluating twostage systems. In this category, the two stages are treated independently (Seiford and Zhu, 1999). Other approaches are also used to measure the efficiency of two-stage structure systems (Cook et al., 2010a; Halkos et al., 2014). In summary, works on twostage systems can be classified broadly into four categories: i) standard two-stage DEA approach proposed by Wang et al. (1997) and Seiford and Zhu (1999); ii) network DEA approach recommended by Färe and Grosskopf (1996), which considers the connection between two stages by treating intermediate measures as unknown decision variables in optimising the overall efficiency of the evaluated DMU; iii) rational two-stage DEA approach proposed by Kao and Kwang (2008) and Chen et al. (2009), which assumes a multiplicative or additive relationship between the overall and divisional efficiencies; and iv) game-theoretic two-stage DEA approach suggested by Liang, Cook and Zhu (2008), which considers the two stages as two players in a game. According to system structure, these two-stage network structure models can be classified into three categories: (a) serial structure models, (b) parallel structure models and (c) mixed structure models. In serial structure models, two or more internal stages are linked by intermediate measures (Tone and Tsutsui 2009; Lozano, 2011, 2015, 2016; Kao 2012a; Khalili-Damghani et al. 2015; An et al. 2016, 2018). In parallel structure models, the individual stages operate similarly to each other. This category is the focus of the current work. Färe and Primont (1984) discussed the efficiency of firms with multiple parallel plants. Kao (1998) applied his methodology to measure the efficiency of forest districts in Taiwan with multiple working circles, where the components are absolutely independent. In addition, in an extension of the independent parallel system, certain resources are shared by several processes. Kao (2009b) evaluated the efficiency of 
parallel production systems, which are composed of independent production units. Zuo and Guan (2017) proposed a parallel DEA model to measure the R\&D efficiency of each region which has multiple independent sub-processes. An extension of this type of model is the shared flow system, in which the inputs are shared among individual stages (Kao 2010). The authors also stated that a parallel model can be considered a special case of a serial model without intermediate measures. Kao (2012b) studied efficiency decomposition for parallel production systems, regarding chemistry departments in the UK as an example. Amirteimoori (2013) suggested a general parallel structure in which several inputs are shared among the individual stages whilst certain inputs are individually used by one stage. Du et al. (2015) recommended a series of DEA models to accommodate settings where non-homogeneous sub-units operate in parallel network structures with intermediate measures. Avkiran (2015) used a dynamic network DEA for analysing commercial banking with a parallel structure in China from 2008 to 2010. Xiong et al. (2017) examined the resource allocation issue in a parallel system according to relationships between two components and applied the related DEA model to the Chinese input-output table. Gong et al. (2018) studied Chinese manufacturers with parallel network structures, where each input or output of the system is not the sum of those of all its components. In mixed structure models, systems with serial and parallel processes are analysed (Lewis and Sexton 2004; Yu and Fan 2009; Avrikan 2009; Moreno and Lozano 2014; Wu et al. 2016b).

The above-mentioned DEA models have been widely applied in supply chain systems and similar structure systems and can help managers identify inefficiencies in network systems. However, previous studies mostly assumed the relationship between stages (subDMUs) in network systems to be unidirectional or independent. Few studies considered the interdependent relationship between the members of a system despite the current prevalence of this relationship (e.g. two production departments in a factory may provide their products, such as parts, to each other.). This paper focuses on a simple but representative parallel interdependent processes system. In such a production system, two subDMUs (stages) provide certain outputs or resources (intermediate 
products) for each other. In this work, we present a new parallel DEA approach to measuring the individual and overall efficiencies of such a parallel interdependent processes system. Unlike authors of previous models, we build an additive DEA model, which considers the overall efficiency to be the weighted average of divisional efficiencies. Moreover, we transfer the original non-linear additive DEA model into a linear one and then decompose the overall efficiency of the system into two divisional efficiencies by setting a priority to one stage of the system. According to these results, each system can detect the weakness in its components to guarantee that proper measures can be implemented to improve system performance.

The rest of this paper is organised as follows. Section 2 builds the approach to the efficiency evaluation of parallel interdependent processes systems. In Section 3, the proposed approach is applied to analyse and identify differences among the Chinese '985 Project' universities. Finally, Section 4 provides the conclusions and future directions of this study.

\section{Additive models for the parallel interdependent processes systems}

In the parallel system considered in this study, parallel stages are not operated independently but interact with each other. One stage invests some of its outputs to another stage and also consumes some of the outputs of another stage. In this system, non-homogenous sub-units operate in parallel network structures with intermediate measures, similar to that in the work of Du et al. (2015). A simple structure with two parallel stages is illustrated in Figure 1.

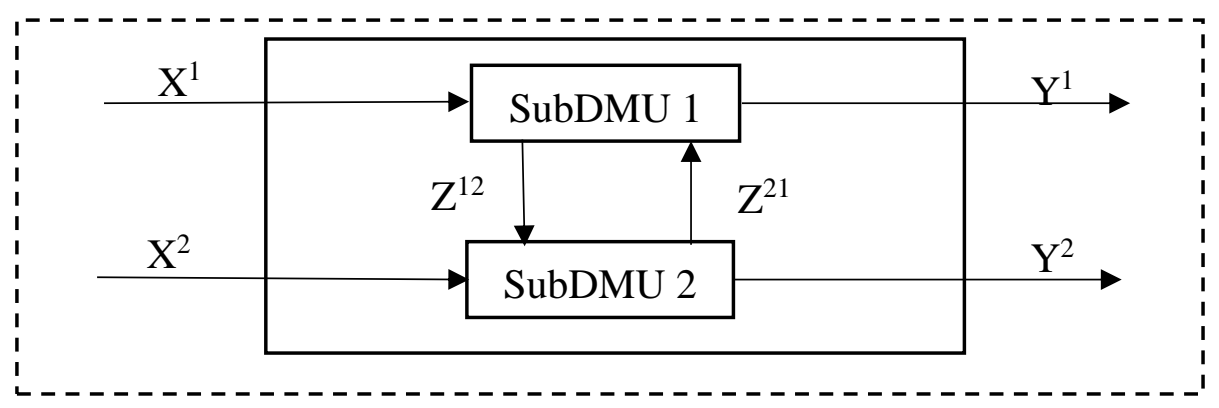

Figure 1. Parallel interdependent processes systems with two subDMUs. 
$n$ DMUs are to be evaluated, where each DMU contains two parallel stages, namely, SubDMU 1 and SubDMU 2. For DMU $\mathrm{DM}_{j}$, SubDMU 1 uses input $X_{j}^{1}$ and outputs from SubDMU $2 Z_{j}^{21}$ to produce the outputs $Z_{j}^{12}$ and $Y_{j}^{1}$, whereas SubDMU 2 utilises input $X_{j}^{2}$ and outputs from SubDMU $1 Z_{j}^{12}$ to generate outputs $Z_{j}^{21}$ and $Y_{j}^{2} \cdot Z_{j}^{12}$ and $Z_{j}^{21}$ are denoted as the intermediate measures of $\mathrm{DMU}_{j}$. $X_{j}^{1} \geq \mathbf{0}, X_{j}^{2} \geq \mathbf{0}, Z_{j}^{21} \geq \mathbf{0}, Z_{j}^{12} \geq \mathbf{0}, Y_{j}^{1} \geq \mathbf{0}, Y_{j}^{2} \geq \mathbf{0}$, and each vector must have at least one positive element. '0' should be noted to be zero vector and differently decided by the dimension of left vectors in the corresponding inequality.

This system slightly resembles to that in Liang et al. (2011) but still distinct from the latter because the two processes in our system work simultaneously, whilst the two processes in the latter have a precedence relationship, in which a feedback connects the second process to the first.

On the basis of the constant returns to scale (CRS) model of Charnes et al. (1978), the CRS efficiency scores for DMU $\mathrm{DM}_{0}$ in SubDMU 1 and SubDMU 2 can be calculated by Models (1) and (2), respectively.

$$
\begin{aligned}
e_{0}{ }^{1}= & \operatorname{Max} \quad \frac{v^{1} Z_{0}^{12}+u Y_{0}^{1}}{w X_{0}^{1}+v^{1} Z_{0}^{21}} \\
\text { s.t. } \quad & \frac{v^{1} Z_{j}^{12}+u Y_{j}^{1}}{w X_{j}^{1}+v^{1} Z_{j}^{21}} \leq 1, \quad j=1, \cdots, n, \\
& v^{1}, u, w, v^{1} \geq \mathbf{0} . \\
e_{0}^{2}= & \operatorname{Max} \quad \frac{v^{2} Z_{0}^{21}+\mu Y_{0}^{2}}{\omega X_{0}^{2}+v^{2} Z_{0}^{12}} \\
\text { s.t. } \quad & \frac{v^{2} Z_{j}^{21}+\mu Y_{j}^{2}}{\omega X_{j}^{2}+v^{2} Z_{j}^{12}} \leq 1, \quad j=1, \cdots, n, \\
& v^{2}, \mu, \omega, v^{2} \geq \mathbf{0} .
\end{aligned}
$$

where $v^{1}, u, w$ and $v^{1}$ are the multipliers of intermediate measure $Z_{j}^{12}$, output $Y_{j}^{1}$, input $X_{j}^{1}$ and intermediate measure $Z_{j}^{21}$, respectively. $v^{2}, \mu, \omega$ and $v^{2}$ are the 
multipliers of intermediate measure $Z_{j}^{12}$, output $Y_{j}^{2}$, input $X_{j}^{2}$ and intermediate measure $Z_{j}^{21}$, respectively. $e_{0}^{1}$ and $e_{0}^{2}$ are the individual efficiencies of SubDMU 1 and SubDMU 2, respectively.

In a two-stage system, where the link from SubDMU 2 to SubDMU 1, i.e. $Z_{j}^{21}$, does not exist, Liang, Cook and Zhu (2008) and Kao and Huwang (2008) stated that applying different DEA models for the two stages separately does not accurately describe the relationship between the entire processes and the two sub-processes. Analogously, Models (1) and (2) cannot be applied separately because doing so will disregard the relationship between the two SubDMUs, which are connected by intermediate measures $Z_{j}^{12}$ and $Z_{j}^{21}$. Model (1) attempts to increase $Z_{j}^{12}$ and reduce $Z_{j}^{21}$, whilst Model (2) attempts to reduce $Z_{j}^{12}$ and increase $Z_{j}^{21}$. An alternative approach to evaluating the performance of the two-stage network is to view the two stages from a centralised perspective and determine a set of optimal weights on the intermediate factors to maximise their efficiency scores (as in a supply chain where the manufacturer and retailer jointly determine the price and order quantity, among others, to achieve maximum profit) (Huang and Li 2001).

Therefore, similar to Kao and Hwang's (2008) assumption on the multipliers of intermediate measures, the assumptions of $v^{1}=v^{2}=v, v^{1}=v^{2}=v$ in Models (1) and (2) are used to link the two subDMUs with the entire processes. Under this assumption, we define the efficiencies of SubDMU 1 and SubDMU 2 by $E_{0}^{1}$ and $E_{0}^{2}$, respectively, and denote $v^{*}, v^{*}, \omega^{*}, u^{*}$ by the optimal solution of the above models. The two stages are proposed to be combined in a weighted average of the efficiency scores of SubDMU 1 and SubDMU 2 as follows:

$$
E_{0}=w e i_{1} * E_{0}^{1}+w e i_{2} * E_{0}^{2}=w e i_{1} * \frac{v^{*} Z_{0}^{12}+u^{*} Y_{0}^{1}}{w^{*} X_{0}^{1}+v^{*} Z_{0}^{21}}+w e i_{2} * \frac{v^{*} Z_{0}^{21}+\mu^{*} Y_{0}^{2}}{\omega^{*} X_{0}^{2}+v^{*} Z_{0}^{12}},
$$


where $w e i_{1}$ and $w e i_{2}$ denote the weights of the subDMUs in the first and second stages, respectively, such that $w e i_{1}+w e i_{2}=1$.

Definition 1. DMU 0 is deemed overall efficient if and only if $E_{0}=1$. The SubDMU 1 (SubDMU 2) of DMU 0 is assumed efficient if and only if $E_{0}^{1}=1 \quad\left(E_{0}^{2}=1\right)$.

According to Definition 1, we have the following theorem about the efficiency of a DMU and its subDMUs.

Theorem 1. DMU $U_{0}$ with two subDMUs is overall efficient if and only if its two subDMUs are efficient, i.e. $E_{0}^{1}=E_{0}^{2}=1$.

Proof. Firstly, we prove the condition $E_{0}^{1}=E_{0}^{2}=1$ is necessary. According to Definition 1, if $\mathrm{DMU}_{o}$ is overall efficient, then $E_{0}=1$; and also because $E_{0}=w e i_{1} * E_{0}^{1}+w e i_{2} * E_{0}^{2}$ and $0 \leq E_{0}^{1} \leq 1,0 \leq E_{0}^{2} \leq 1$, we can obtain $E_{0}^{1}=E_{0}^{2}=1$.

Then, we prove that the condition $E_{0}^{1}=E_{0}^{2}=1$ is sufficient. If its two subDMUs are efficient, i.e. $E_{o}{ }^{1}=E_{0}{ }^{2}=1$, then we have $E_{0}=w e i_{1} * E_{0}^{1}+w e i_{2} * E_{0}^{2}=1$. According to Definition 1, DMU is overall efficient.

To sum up, $\mathrm{DMU}_{o}$ considering the sub-DMUs in Stages 1 and 2 is overall efficient if and only if its two subDMUs are efficient.

In Formula (3), wei and $w e i_{2}$ signify the relative importance or contribution of the efficiency of each stage to the overall performance of the provided DMU in the entire process. A reasonable weight choice of each stage is the proportion of the total resources devoted to each stage; this weight choice reflects the relative size and importance of a stage (Amirteimoori 2013; Chen et al. 2009, 2008; Cook et al. 2010b). Therefore, the weights are defined as follows:

$$
w e i_{1}=\frac{w^{*} X_{0}^{1}+v^{*} Z_{0}^{21}}{w^{*} X_{0}^{1}+v^{*} Z_{0}^{21}+\omega^{*} X_{0}^{2}+v^{*} Z_{0}^{12}}, \quad w e i_{2}=\frac{\omega^{*} X_{0}^{2}+v^{*} Z_{0}^{12}}{w^{*} X_{0}^{1}+v^{*} Z_{0}^{21}+\omega^{*} X_{0}^{2}+v^{*} Z_{0}^{12}},
$$


where $w^{*} X_{0}{ }^{1}+v^{*} Z_{0}{ }^{21}+\omega^{*} X_{0}{ }^{2}+v^{*} Z_{0}{ }^{12}$ represents the total amount of input resources consumed by the entire two-stage network processes and $w^{*} X_{0}{ }^{1}+v^{*} Z_{0}{ }^{21}$ and $\omega^{*} X_{0}{ }^{2}+v^{*} Z_{0}^{12}$ denote the sizes of the first and second stages, respectively. With the expression of $w e i_{1}$ and $w e i_{2}, E_{0}=\frac{v^{*} Z_{0}^{12}+u^{*} Y_{0}^{1}+v^{*} Z_{0}^{21}+\mu^{*} Y_{0}^{2}}{w^{*} X_{0}^{1}+v^{*} Z_{0}^{21}+\omega^{*} X_{0}^{2}+v^{*} Z_{0}^{12}}$ is given.

Thus, the overall efficiency of the entire two-stage parallel interdependent processes systems for a common $\mathrm{DMU}_{0}$ can be evaluated by solving the following fractional model (Model (5)) under CRS.

$$
\begin{aligned}
E_{0}= & \max \quad \frac{v Z_{0}^{12}+u Y_{0}^{1}+v Z_{0}^{21}+\mu Y_{0}^{2}}{w X_{0}^{1}+v Z_{0}^{21}+\omega X_{0}^{2}+v Z_{0}^{12}} \\
\text { s.t. } \quad & \frac{v Z_{j}^{12}+u Y_{j}^{1}}{w X_{j}^{1}+v Z_{j}^{21}} \leq 1, \quad j=1, \ldots, n, \\
& \frac{v Z_{j}^{21}+\mu Y_{j}^{2}}{\omega X_{j}^{2}+v Z_{j}^{12}} \leq 1, \quad j=1, \ldots, n, \\
& \frac{w X_{0}^{1}+v Z_{0}^{21}}{w X_{0}^{1}+v Z_{0}^{21}+\omega X_{0}^{2}+v Z_{0}^{12}} \geq \alpha, \\
& \frac{\omega X_{0}^{2}+v Z_{0}^{12}}{w X_{0}^{1}+v Z_{0}^{21}+\omega X_{0}^{2}+v Z_{0}^{12}} \geq \beta, \\
& w, \omega, v, v, u, \mu \geq \mathbf{0} .
\end{aligned}
$$

where $\alpha$ and $\beta$ represent the minimum weights for SubDMU 1 and SubDMU 2, respectively, in calculating the overall efficiency of a DMU. Model (5) is a nonlinear program that needs to be transformed into a standard linear program (6) through Charnes-Cooper transformation.

Let $\quad t=\frac{1}{w X_{0}^{1}+v Z_{0}^{21}+\omega X_{0}^{2}+v Z_{0}^{12}}, \quad w^{\prime}=w t, \quad \omega^{\prime}=\omega t, \quad u^{\prime}=u t, \quad \mu^{\prime}=\mu t$, $v^{\prime}=v t$ and $v^{\prime}=v t$; the above-mentioned model can be transformed into the following linear program: 


$$
\begin{aligned}
E_{0}= & \max \quad v^{\prime} Z_{0}^{12}+u^{\prime} Y_{0}^{1}+v^{\prime} Z_{0}^{21}+\mu^{\prime} Y_{0}^{2} \\
\text { s.t. } \quad & v^{\prime} Z_{j}^{12}+u^{\prime} Y_{j}^{1}-\left(w^{\prime} X_{j}^{1}+v^{\prime} Z_{j}^{21}\right) \leq 0, j=1, \ldots, n, \\
& v^{\prime} Z_{j}^{21}+\mu^{\prime} Y_{j}^{2}-\left(\omega^{\prime} X_{j}^{2}+v^{\prime} Z_{j}^{12}\right) \leq 0, j=1, \ldots, n, \\
& w^{\prime} X_{0}^{1}+v^{\prime} Z_{0}^{21}+\omega^{\prime} X_{0}^{2}+v^{\prime} Z_{0}^{12}=1, \\
& w^{\prime} X_{0}^{1}+v^{\prime} Z_{0}^{21} \geq \alpha, \\
& \omega^{\prime} X_{0}^{2}+v^{\prime} Z_{0}^{12} \geq \beta, \\
& w^{\prime}, \omega^{\prime}, v^{\prime}, v^{\prime}, u^{\prime}, \mu^{\prime} \geq \mathbf{0} .
\end{aligned}
$$

Once an optimal solution of Model (6) is obtained, the additive efficiency score for the two-stage parallel interdependent processes systems can be calculated accordingly. Model (6) is different from the work of Kao (2009b) in that the subDMUs are independent of each other and the overall efficiency is measured by only maximising the weighted final outputs. We extend the above model to include the interrelationship of subDMUs as follows:

$$
\begin{aligned}
E_{0}= & \max \quad u^{\prime} Y_{0}^{1}+\mu^{\prime} Y_{0}^{2} \\
s . t . \quad & v^{\prime} Z_{j}^{12}+u^{\prime} Y_{j}^{1}-\left(w^{\prime} X_{j}^{1}+v^{\prime} Z_{j}^{21}\right) \leq 0, j=1, \ldots, n, \\
& v^{\prime} Z_{j}^{21}+\mu^{\prime} Y_{j}^{2}-\left(\omega^{\prime} X_{j}^{2}+v^{\prime} Z_{j}^{12}\right) \leq 0, j=1, \ldots, n, \\
& v^{\prime} Z_{0}^{12}+u^{\prime} Y_{0}^{1}-\left(w^{\prime} X_{0}^{1}+v^{\prime} Z_{0}^{21}\right)+s_{0}^{1}=0, \\
& v^{\prime} Z_{j}^{21}+\mu^{\prime} Y_{j}^{2}-\left(\omega^{\prime} X_{j}^{2}+v^{\prime} Z_{j}^{12}\right)+s_{0}^{2}=0, \\
& w^{\prime} X_{0}^{1}+\omega^{\prime} X_{0}^{2}=1, \\
& w^{\prime} X_{0}^{1}+v^{\prime} Z_{0}^{21} \geq \alpha, \\
& \omega^{\prime} X_{0}^{2}+v^{\prime} Z_{0}^{12} \geq \beta, \\
& w^{\prime}, \omega^{\prime}, v^{\prime}, v^{\prime}, u^{\prime}, \mu^{\prime}, s_{0}^{1}, s_{0}^{2} \geq \mathbf{0} .
\end{aligned}
$$

Kao's model differs from the proposed one (Model (6)). Hence, the overall and divisional efficiencies should also be distinct. A disadvantage of Kao's (2009b) model is it considers the initial inputs and the final outputs only, thereby ignoring the potential effect of each (sub) DMU on the calculation of the overall efficiency (because in Kao's model, each system's efficiency is regarded as an efficiency constraint only). In other words, Kao's (2009b) model, similar to traditional DEA models, considers the network system as a 'black box' when calculating this system's overall efficiency. 
Assume that $\left(w^{\prime^{*}}, v^{\prime^{*}}, \omega^{\prime^{*}}, v^{\prime^{*}}, u^{\prime^{*}}, \mu^{\prime *}, s_{0}^{1^{*}}, s_{0}^{2^{*}}\right)$, the divisional efficiency of the first stage is $1-s_{0}^{1^{*}} /\left(w^{\prime^{*}} X_{0}^{1}+v^{\prime^{*}} Z_{0}^{21}\right)$, the efficiency of the second stage is 1 $s_{0}^{2^{*}} /\left(\omega^{\prime^{*}} X_{j}^{2}+v^{\prime^{*}} Z_{j}^{12}\right)$ and the overall efficiency is $u^{\prime^{*}} Y_{0}^{1}+\mu^{\prime^{*}} Y_{0}^{2}$. With the application of Kao's (2009b) model, the overall efficiency of a system does not have a clear relationship with the divisional efficiencies. In the proposed model (Model (6')), the overall efficiency is defined as the weighted sum of the two divisional efficiencies, which can be seen in Formula (3) and Model (6) (where $E_{0}=w e i_{1} * E_{0}^{1}+w e i_{2} * E_{0}^{2}$ ).

Model (6) may have multiple optimal solutions. Thus, the respective efficiencies of the subDMUs may not be unique. A unique set of multipliers can be identified by following Kao and Hwang's (2008) approach; this set produces the highest efficiency score of SubDMU 1 or SubDMU 2 whilst maintaining the overall efficiency score on the entire network processes. Denote $E_{0}$ by the overall efficiency of DMU0, which is the optimal objective value of Model (6). $w^{\prime *} X_{0}{ }^{1}+v^{\prime *} Z_{0}{ }^{21}+\omega^{\prime *} X_{0}{ }^{2}+v^{\prime *} Z_{0}{ }^{12}=1$ is satisfied for any optimal solution of model (6); thus, wei $=w^{\prime *} X_{0}{ }^{1}+v^{\prime *} Z_{0}{ }^{21}$ and $w e i_{2}=1-w e i_{1} \quad$ can be obtained.

A procedure for obtaining the unique solution is to maximise the achievable efficiency value of SubDMU 1 whilst retaining the overall efficiency score. The value can be determined by the following:

$$
\begin{aligned}
E_{0}^{1}= & \max \quad v^{\prime \prime} Z_{0}^{12}+u^{\prime \prime} Y_{0}^{1} \\
\text { s.t. } & v^{\prime \prime} Z_{j}^{12}+u^{\prime \prime} Y_{j}^{1}-\left(w^{\prime \prime} X_{j}^{1}+v^{\prime \prime} Z_{j}^{21}\right) \leq 0, j=1, \ldots, n, \\
& v^{\prime \prime} Z_{j}^{21}+\mu^{\prime \prime} Y_{j}^{2}-\left(\omega^{\prime \prime} X_{j}^{2}+v^{\prime \prime} Z_{j}^{12}\right) \leq 0, j=1, \ldots, n, \\
& w^{\prime \prime} X_{0}^{1}+v^{\prime \prime} Z_{0}^{21}=1, \\
& v^{\prime \prime} Z_{0}^{12}+u^{\prime \prime} Y_{0}^{1}+v^{\prime \prime} Z_{0}^{21}+\mu^{\prime \prime} Y_{0}^{2}-E_{0}\left(w^{\prime \prime} X_{0}^{1}+v^{\prime \prime} Z_{0}^{21}+\omega^{\prime \prime} X_{0}^{2}+v^{\prime \prime} Z_{0}^{12}\right)=0, \\
& \alpha\left(w^{\prime \prime} X_{0}^{1}+v^{\prime \prime} Z_{0}^{21}+\omega^{\prime \prime} X_{0}^{2}+v^{\prime \prime} Z_{0}^{12}\right)-\left(w^{\prime \prime} X_{0}^{1}+v^{\prime \prime} Z_{0}^{21}\right) \leq 0, \\
& \beta\left(w^{\prime \prime} X_{0}^{1}+v^{\prime \prime} Z_{0}^{21}+\omega^{\prime \prime} X_{0}^{2}+v^{\prime \prime} Z_{0}^{12}\right)-\left(\omega^{\prime \prime} X_{0}^{2}+v^{\prime \prime} Z_{0}^{12}\right) \leq 0, \\
& w^{\prime \prime}, \omega^{\prime \prime}, v^{\prime \prime}, v^{\prime \prime}, u^{\prime \prime}, \mu " \geq \mathbf{0} .
\end{aligned}
$$


SubDMU 2's efficiency score for $\mathrm{DMU}_{0}$ can then be calculated as $E_{0}^{2}=\frac{E_{0}-w e i_{1} E_{0}^{1}}{w e i_{2}}$, where $w e i_{1}$ and $w e i_{2}$ are the optimal weights based on Model (6) and $E_{0}^{1}$ is the optimal efficiency reached whilst the overall efficiency in Model (7) is maintained.

Analogously, the following linear program can be established to maximise the efficiency score of SubDMU 2, i.e. $E_{0}^{2}$, whilst maintaining the overall efficiency score of $E_{0}$.

$$
\begin{array}{ll}
E_{0}^{2}=\max & v^{\prime} Z_{0}^{21}+\mu^{\prime} Y_{0}^{2} \\
\text { subject to } & v^{\prime} Z_{j}^{12}+u^{\prime} Y_{j}^{1}-\left(w^{\prime} X_{j}^{1}+v^{\prime} Z_{j}^{21}\right) \leq 0, j=1, \ldots, n, \\
& v^{\prime} Z_{j}^{21}+\mu^{\prime} Y_{j}^{2}-\left(\omega^{\prime} X_{j}^{1}+v^{\prime} Z_{j}^{12}\right) \leq 0, j=1, \ldots, n, \\
& \omega^{\prime} X_{0}^{1}+v^{\prime} Z_{0}^{12}=1, \\
& v Z_{0}^{12}+u Y_{0}^{1}+v Z_{0}^{21}+\mu Y_{0}^{2}-E_{0}\left(w^{\prime} X_{0}^{1}+v^{\prime} Z_{0}^{21}+\omega^{\prime} X_{0}^{2}+v^{\prime} Z_{0}^{12}\right)=0, \\
& \alpha\left(w^{\prime} X_{0}^{1}+v^{\prime} Z_{0}^{21}+\omega^{\prime} X_{0}^{2}+v^{\prime} Z_{0}^{12}\right)-\left(w^{\prime} X_{0}^{1}+v^{\prime} Z_{0}^{21}\right) \leq 0, \\
& \beta\left(w^{\prime} X_{0}^{1}+v^{\prime} Z_{0}^{21}+\omega^{\prime} X_{0}^{2}+v^{\prime} Z_{0}^{12}\right)-\left(\omega^{\prime} X_{0}^{2}+v^{\prime} Z_{0}^{12}\right) \leq 0, \\
& w^{\prime}, \omega^{\prime}, v^{\prime}, v^{\prime}, u^{\prime}, \mu^{\prime} \geq \mathbf{0} .
\end{array}
$$

The first-stage efficiency score for $\mathrm{DMU}_{0}$ can be computed as $E_{0}^{1^{\prime}}=\frac{E_{0}-w e i_{2} E_{0}^{2}}{w e i_{1}}$, where $w e i_{1}$ and $w e i_{2}$ are the optimal weights of Model (6). $E_{0}^{2}$ represents the optimal efficiency reached whilst the overall efficiency in Model (8) is maintained.

On the basis of the illustrations in the preceding paragraphs, the divisional efficiencies $E_{0}^{1}, E_{0}^{2^{\prime}}$ and $E_{0}^{1^{\prime}}, E_{0}^{2}$ can be obtained in two scenarios through Models (7) and (8). When the aforementioned results satisfy $E_{0}^{1}=E_{0}^{1^{\prime}}$ or $E_{0}^{2}=E_{0}^{2}$, a unique efficiency decomposition of the overall efficiency can be concluded.

In a traditional parallel system, each parallel stage operates independently. Hence, DEA models can be developed without considering the interaction between the parallel stages. By contrast, this study explores a new parallel system by considering the 
interaction between parallel stages, the structure of which is universal in many production processes. To be precise, each parallel stage produces an immediate output into another parallel stage. Therefore, the proposed DEA model in this study considers the different immediate outputs between parallel stages.

\section{Application to '985 Project' universities in China}

In this section, the newly developed approach is applied to evaluate the 2012 performance of the Chinese universities in the '985 Project', a constructive project conducted by the government of the People's Republic of China. This project was introduced by the former General Secretary of the Communist Party of China and former President Jiang Zemin at the Centenary Celebration of Peking University on May 4, 1998 to promote the development and reputation of the Chinese higher education system by founding world-class universities in the 21 st century. It was eponymously named after the date of the announcement, May 1998 or 98/5, according to the Chinese date format. The project involves national and local governments, allocating large amounts of funding to certain universities to build new research centres, improve facilities, hold international conferences, attract world-renowned faculty and visiting scholars and help Chinese faculty attend conferences abroad. In the initial phase, nine universities were included in the project. Thirty-nine universities (commonly accepted as first-class Chinese universities) were sponsored by the end of the project's second phase. The project stopped accepting new schools in 2011 (Zhang et al. 2013). Data from the National University of Defense Technology were not announced because of security concerns and are therefore not included in our analysis of the '985 Project' universities.

The '985 Project' is a critical component of one of the largest sustained increases of investment in university research in human history. During 2009 and 2013, China's total university research funds increased to 264.769 billion RMB, 52.7\% of which was for the '985 Project' universities. The effects of the project were also evident. According to data from the Institute of Scientific and Technical Information of China, 
the number of international Science Citation Index (SCI) publications was 231.4 thousand in 2013, which ranked second worldwide, followed by America. In 2009 and 2013, papers from the '985 Project' universities accounted for approximately $47 \%$ of all high-quality papers, including SCI publications and national high-level publications. To evaluate the results of the '985 Project', the universities' research performance must be investigated.

Figure 2 shows that the researchers and sizes of a university are the inputs of the research development process of each university. Corresponding outputs are the numbers of high-quality papers (HQP), scientific books (SB) and national scientific awards (NSA), which become the inputs of the research application process. The research development $(\mathrm{RD})$ process for obtaining high-quality papers, scientific books and national scientific awards can directly reflect the research development capability of a university. In addition, the number of first-level disciplines authorised to offer a doctorate degree (FLDD) is an input of the research application process, whereas the research funds and technology transfer incomes (TTI) are the outputs of the research application process. The research funds (RF) flow is an output from the research application process to the research development process. FLDD is selected as an input of the research application process because it can reflect the comprehensive strength of the disciplines of a university, which highly determines the success of the institution's fund application and technology transfer. Technology transfer incomes refer to the cost that the user pays to the university when a university transfers its technology to others or provides its technology to others for use. The research application (RA) process reflects the research application capability of a university, i.e. the capacity to apply its research achievements to real production scenarios. According to the above illustrations, high-quality papers, scientific books and research funds can be deemed intermediate products of the universities, which are the major inputs to one subDMU (RD or RA) and major outputs to other subDMUs (RA or RD). 


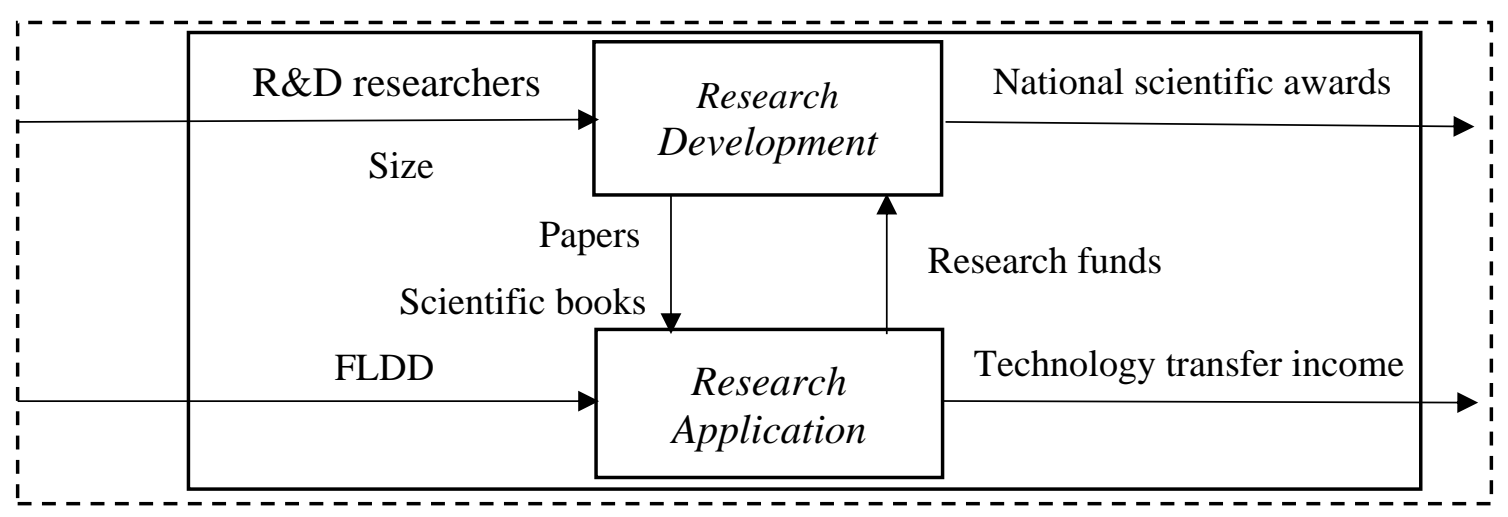

Figure 2. Structure of research outcome in universities.

The 38 universities are institutions of higher learning that are directly under the Ministry of Education of China or Chinese Academy of Sciences. Several important inputs or outputs are as follows. Researchers include all teachers, research scientists and engineers related to $R \& D$ activities. National scientific awards refer to the total number of National Natural Science Prizes, National Invention Awards and National Science and Technology Progress Awards that a university garnered in the year. Highquality papers comprise publications in the science citation indexed journal and Chinese comprehensive core journals. The data are collected from the '2013 Statistics for Colleges and Universities Directly under the Ministry of Education', '2013 China Science and Technology Statistics and Analysis Report' and '2013 Statistics Assembly of Higher School Science and Technology Statistics'. The size of the university is in $10,000 \mathrm{~m}^{2}$, and technology transfer incomes and research funds are in 1,000 RMB. Descriptive statistics of these universities are shown in Table 1.

Table 1. Descriptive statistics on 38 universities in China

\begin{tabular}{lllllllll}
\hline Universities & Researchers & Size & NSA & SB & HQP & FLDD & TTI & RF \\
\hline Mean & 2421.132 & 318.636 & 39.684 & 20.316 & 2491.737 & 29.39 & 37049.55 & 1466592 \\
Median & 1722 & 319.1 & 34 & 16 & 1951.5 & 27 & 4180 & 1330057 \\
S.D. & 1948.052 & 146.634 & 30.708 & 15.068 & 1741.313 & 11.317 & 99273.01 & 923955.9 \\
Max. & 8501 & 611 & 122 & 56 & 6730 & 58 & 554753 & 3930860 \\
Min & 124 & 37.80 & 0 & 0 & 101 & 5 & 0 & 10756 \\
\hline
\end{tabular}


The efficiency of the research development process reflects the performance in winning national scientific awards and publishing scientific books and papers, whereas the efficiency of the research application process reflects the performance in generating research funds and technology transfer incomes. To avoid assigning extreme weights for the two stages, the weights of each subDMU's efficiency to the overall efficiency are set to be not smaller than 0.1, i.e. $\alpha=\beta=0.1$. We check all values of $\alpha$ and $\beta$ when they are between $[0.05,0.25]$ and find only several slight differences. Through Model (6), the overall efficiencies of these universities can be calculated, and these results are shown in column 2 of Table 2 . In this case, we investigate the divisional efficiencies after acquiring the overall efficiencies of Model (6) and find no differences between the two divisional efficiencies regardless of which process is prioritised. Here, the efficiency of the research development process, $E_{0}^{1}$, is selected to be measured first, followed by the research application process, $E_{0}^{2} . E_{0}^{1}$ can be obtained with the adoption of Model (7), and the efficiency of the research development process can be acquired with use of $E_{0}^{2}=\left(E_{0}-w e i_{1} E_{0}^{1}\right) / w e i_{2}$. The efficiencies of the two stages of all the universities are given in columns 3 and 4 of Table 2.

Table 2. Efficiencies of universities

\begin{tabular}{cccc}
\hline Universities & Overall efficiency & SubDMU 1's efficiency & SubDMU 2's efficiency \\
\hline PKU & 0.616 & 0.930 & 0.205 \\
RUC & 0.404 & 0.465 & 0.188 \\
TSU & $\mathbf{1 . 0 0 0}$ & $\mathbf{1 . 0 0 0}$ & $\mathbf{1 . 0 0 0}$ \\
BUAA & $\mathbf{1 . 0 0 0}$ & $\mathbf{1 . 0 0 0}$ & $\mathbf{1 . 0 0 0}$ \\
BIT & 0.548 & 0.240 & 0.793 \\
CAU & 0.612 & 0.650 & 0.271 \\
BNU & 0.591 & 1.000 & 0.152 \\
CUN & 0.507 & 1.000 & 0.015 \\
NKU & 0.430 & 0.544 & 0.210 \\
TU & 0.786 & 0.814 & 0.542 \\
DUST & 0.570 & 0.687 & 0.252 \\
NEU & 0.973 & 1.000 & 0.738 \\
JLU & 0.363 & 0.508 & 0.317 \\
HIT & 0.635 & 1.000 & 0.439 \\
FDU & 0.637 & 0.948 & 0.433 \\
TJU & 0.664 & 0.659 & 0.702 \\
& & 16 &
\end{tabular}




\begin{tabular}{clll} 
SJTU & 0.912 & 0.885 & 0.958 \\
ECNU & 0.436 & 0.604 & 0.132 \\
NJU & 0.539 & 0.871 & 0.143 \\
SEU & 0.866 & 0.929 & 0.497 \\
ZJU & 0.728 & 0.783 & 0.239 \\
USTC & 0.508 & 0.587 & 0.350 \\
XMU & 0.932 & 1.000 & 0.322 \\
SDU & 0.400 & 0.465 & 0.288 \\
OUC & 0.602 & 1.000 & 0.156 \\
WHU & 0.928 & 1.000 & 0.276 \\
HUST & 0.488 & 0.577 & 0.424 \\
HNU & 0.495 & 0.526 & 0.369 \\
CSU & 0.724 & 0.766 & 0.343 \\
SYSU & 0.393 & 0.515 & 0.307 \\
SCUT & 0.515 & 0.554 & 0.370 \\
CQU & 0.824 & 0.888 & 0.279 \\
SCU & 0.529 & 0.755 & 0.151 \\
UESTC & 0.546 & 0.405 & 0.638 \\
XJTU & 0.697 & 0.751 & 0.212 \\
NPU & 0.571 & 0.151 & 0.983 \\
NAFU & 0.367 & 0.207 & 0.441 \\
LZU & 0.551 & 0.592 & 0.179 \\
Average & 0.629 & 0.717 & 0.403 \\
\hline
\end{tabular}

Table 2 shows that Tsinghua University (TSU) and Beihang University (BUAA) were overall efficient. The average overall efficiency of all universities is 0.616 . In addition, given that all the '985 Project' universities are considered the best in China, the increasing support may be intensifying the competition amongst the elite universities. Furthermore, the enhanced competition and cooperation between the '985 Project' universities resulted in the creation of a vibrant national university research ecosystem, which might have led to the good average performance of these universities. The average efficiency of the research development process is also higher than that of the research application process, which indicates that these universities performed relatively well in generating various scientific papers and books and in garnering numerous national scientific awards but did not considerably attract technology transfer incomes and research funds. 
Table 2 denotes that most of the universities performed well in the research development process. These universities focused more and allocated more resources to the research development stage than to the research application stage because a high research publication score meant that they could acquire increased government financial support and attract good students. This approach is common amongst universities in China. To comprehensively improve overall efficiency, these universities should extend the transformation of scientific and technological achievements to real production in a variety of forms and promote their scientific resource superiority into realistic productivity. The Central University for Nationalities (CUN) should be noted as a special case by these universities. CUN had minimal efficiency in the research application process because it is an institution of nationalities that have no industrial technologies for transformation. Table 2 illustrates that few universities performed well in the research application process, such as Beijing Institute of Technology (BIT) and Northwestern Polytechnical University (NPU), which belong to the same organisation as does the Ministry of Industry and Information Technology. The relatively good performance in the research application process was probably due to these institutions' specialisation in navigation, engineering and materials science, whose technologies are easily adopted into industrial processes.

An efficiency map of these provinces is drawn in Figure 3 according to the location of these universities. An efficiency of $0.8-1$ is regarded as high, $0.7-0.8$ as relatively high, $0.6-0.7$ as median, $0.5-0.6$ as relatively low and below 0.5 as low. The white regions in the map have no '985 Project' universities and thus have no data. This efficiency map indicates that the universities' efficiencies had evident regional characteristics. These universities are divided into three categories on the basis of their location: east, central and west universities. East universities are those in Beijing, Tianjin, Hebei, Liaoning, Shanghai, Jiangsu, Zhejiang, Fujian, Shandong, Guangdong and Hainan. Central universities are those in Shanxi, Jilin, Heilongjiang, Anhui, Jiangxi, Henan, Hubei and Hunan. West universities are those in Chongqing, Sichuan, Shaanxi, 
Gansu and other regions. The details of the universities in each category are shown in Table 3.

Table 3. Universities in three areas

\begin{tabular}{ll}
\hline Area & Universities \\
\hline \multirow{2}{*}{ East } & PKU, RUC, TSU, BUAA, BIT, CAU, BNU, CUN, NKU, TU, DUST, NEU, \\
Central & FDU, TJU, SJTU, ECNU, NJU, SEU, ZJU, XMU, SDU, OUC, SYSU, SCUT, \\
West & CLU, HIT, USTC, WHU, HUST, HNU, CSU \\
\hline
\end{tabular}

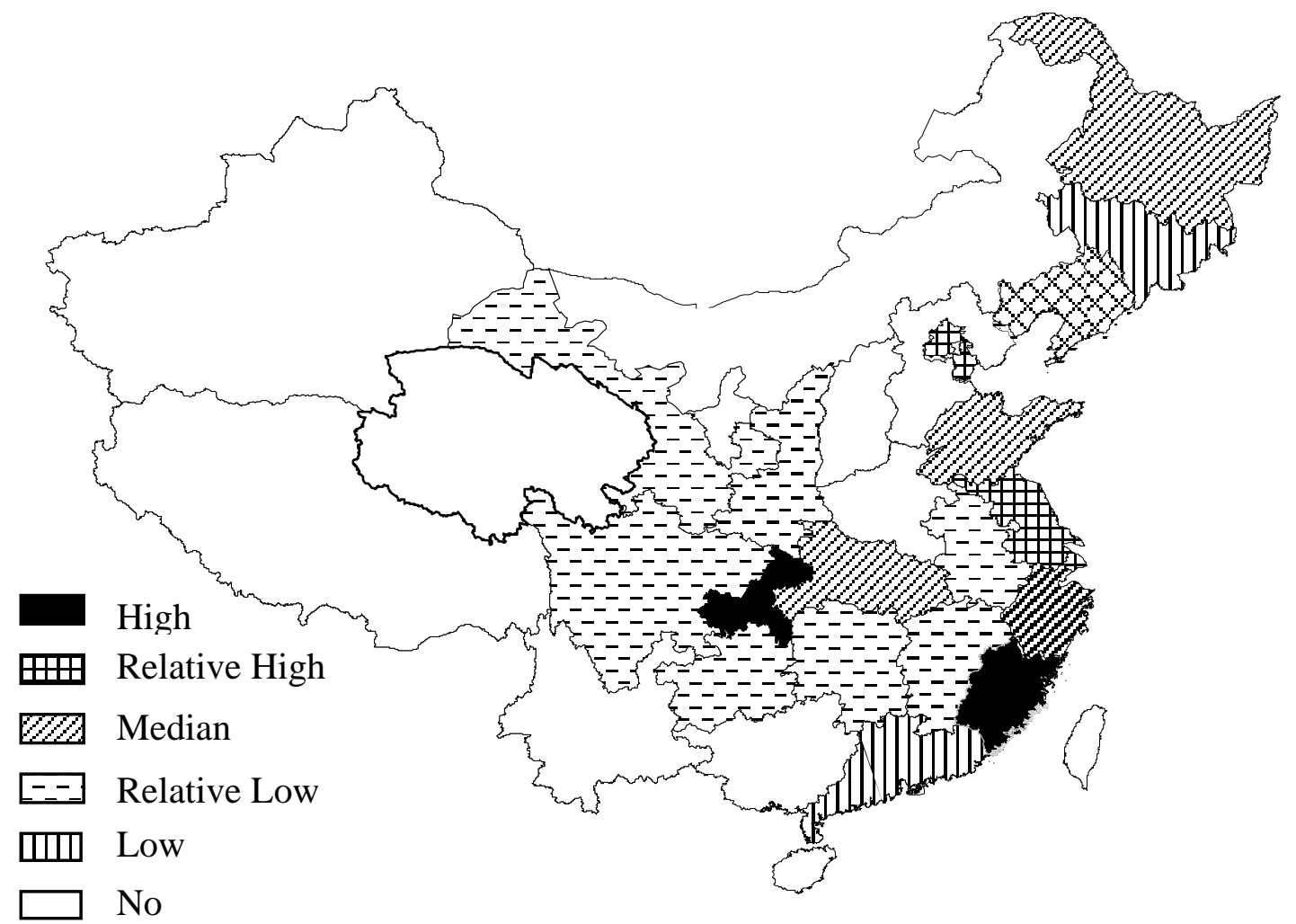

Figure 3. Overall efficiency of universities in China's provinces. 
The overall and divisional efficiencies of the three areas can be obtained by averaging each efficiency listed in Table 2 . The results are given in Table 4.

Table 4. Efficiencies of three areas

\begin{tabular}{cccc}
\hline Area & Overall efficiency & Research development & Research application \\
\hline East & 0.653 & 0.773 & 0.413 \\
Central & 0.592 & 0.709 & 0.360 \\
West & 0.583 & 0.535 & 0.412 \\
\hline
\end{tabular}

Table 4 shows that the east universities had the best overall efficiency in the research development and research application processes amongst the three groups. The overall efficiencies of the central universities were similar to those of the west universities. However, the central universities performed better in research development than did the west universities, whilst the latter performed better in research application than did the former. A comparison between the efficiencies of research development and research application of each area indicates that the former process was higher than the latter process, implying that the '985 Project' universities had, on average, a good capability to write books, publish papers and win national scientific awards. However, they had a weak capability for bringing technology transfer incomes and research funds, especially the central universities. This phenomenon might be due to the heightened emphasis that these universities dedicated to research achievement, which involved writing books and papers and winning awards, because these factors are directly related to the promotion of researchers (teachers). Technology transformation was first implemented in China's universities in the late 1980s. For example, the University of Science and Technology of China (USTC) established the Scientific and Technological Development Corporation and Institution in 1988, whilst the Huazhong University of Science and Technology (HUST) founded a technology transformation office in 1989. Subsequently, new universities began to build institutions related to technology transfer and incubation. This task has not been the main focus of universities until now. The east, central and west areas substantially differ in economy. The performance of the 
universities in these regions might be related to their economic levels. To validate this hypothesis, the correlation coefficient between the efficiencies and the local economy (represented by per capita income) is computed. The correlation coefficients are shown in Table 5.

Table 5. Correlation coefficient between per capita GDP and efficiencies

\begin{tabular}{|c|c|c|c|c|}
\hline & Per capita GDP & $\begin{array}{l}\text { Overall } \\
\text { efficiency }\end{array}$ & $\begin{array}{l}\text { Research } \\
\text { development's } \\
\text { efficiency }\end{array}$ & $\begin{array}{l}\text { Research } \\
\text { application's } \\
\text { efficiency }\end{array}$ \\
\hline Per capita GDP & 1 & & & \\
\hline Overall efficiency & 0.1631 & 1 & & \\
\hline $\begin{array}{l}\text { Research development's } \\
\text { efficiency }\end{array}$ & 0.2482 & 0.6807 & 1 & \\
\hline $\begin{array}{l}\text { Research application's } \\
\text { efficiency }\end{array}$ & 0.1533 & 0.4967 & -0.1024 & 1 \\
\hline
\end{tabular}

Table 5 illustrates that the correlation coefficient between the per capita GDP and overall efficiency, research development process' efficiency and research development application process' efficiency are $0.1631,0.22482$ and 0.1533 , respectively. This finding implies that the universities' research performance had a minimal relation with the economy. A university in a region with a low economic level probably had high efficiency, such as Wuhan University (WHU), Central South University (CSU) and Chongqing University (CQU). Moreover, the correlation coefficient between the overall efficiency and research development process' efficiency was 0.6807 , and that between the overall efficiency and research application process efficiency was 0.4967. These results reveal that the average overall efficiency of the Chinese '985 Project' universities was mainly decided by the research development process efficiency in the current situation possibly due to the universities' increased focus on research development process performance. However, from another viewpoint, most inefficiencies were caused by the research application process. This finding can be verified by the results in Table 2, in which the average efficiency of the research application process of these universities is merely 0.403 . Thus, a university should 
improve not only the performance of its research development process (research development capability) but also that of the research application process (research application capability) to be overall efficient.

\section{Conclusions and future directions}

Efficiency evaluation is an important issue for an organisation in gauging its own performance, especially its weakness. Many conventional DEA and two-stage models have been built to measure the efficiency of a system. However, these models are deficient in that the efficiencies of the entire processes and the two sub-processes are calculated independently or without considering the interdependent relationship amongst the system. In the current work, a new structure of a two-stage parallel system is proposed, where the interdependent relationship between the two subDMUs is considered. An additive DEA approach is provided to measure the overall and divisional efficiencies of the parallel system. The overall efficiency of DMU and divisional efficiency are defined in this new structure, and the necessary and sufficient conditions of being an overall efficiency of DMU are provided. On the basis of the approach used in this study, the source, which causes the inefficiency of a system, can be detected to enable appropriate efforts to be dedicated specifically to improving performance.

The '985 Project' universities in China are analysed in this study by dividing a university's research performance into two parallel subDMUs that provide products or funds to each other to support their operations. Results show that the approach can fully measure the inefficiencies in the parallel interdependent processes system and find the relationship between the overall efficiency and divisional efficiencies. These universities are known to perform better in publishing papers and books and winning national scientific awards than in transferring their technology into real-life production in firms. The results are consistent with the common sense of Chinese people with regard to these universities, which focus more on research development than on 
research application. This application verifies the effectiveness of the proposed approach.

The relationship between the system and process efficiencies, which holds for the case of constant returns to scale, can be extended to the case of variable returns to scale. Besides, this study points to future theoretical research in three interesting directions: (1) developing a model that measure this parallel system when two subDMUs compete or cooperate; (2) building a general model for a system with more than two subDMUs and (3) extending the additive DEA model proposed in this work to other DEA models, including slack-based measures. 


\section{References}

[1] Amirteimoori, A. (2013). A DEA two-stage decision processes with shared resources. Central European Journal of Operations Research, 21(1), 141-151.

[2] An, Q. X., Yan, H., Wu, J., \& Liang, L. (2016). Internal resource waste and centralization degree in two-stage systems: an efficiency analysis. Omega. 61. 8999.

[3] An, Q., Meng, F., Ang, S., \& Chen, X. (2018). A new approach for fair efficiency decomposition in two-stage structure system. Operational Research, 18(1), 257272.x

[4] Avkiran, N. K. (2015). An illustration of dynamic network DEA in commercial banking including robustness tests. Omega. 55. 141-150.

[5] Charnes, A., Cooper, W. W., \& Rhodes, E. (1978). Measuring the productivity ratio of decision making units, European Journal of Operational Research, 2(6), $429-444$.

[6] Chen, Y., Cook, W. D., Li, N., \& Zhu, J. (2008). Additive efficiency decomposition in two-stage DEA, in: Proceedings of the 39th Annual Meeting of the Decision Sciences Institute.

[7] Chen, Y., Cook, W. D., Li, N., \& Zhu, J. (2009). Additive efficiency decomposition in two-stage DEA. European Journal of Operational Research, 196(3), 1170-1176.

[8] Cook, W. D., Liang, L., \& Zhu, J. (2010a). Measuring performance of two-stage network structures by DEA: A review and future perspective, Omega, 38, 423-430.

[9] Cook, W. D., Zhu, J., Bi, G., \& Yang, F. (2010b). Network DEA: Additive efficiency decomposition. European Journal of Operational Research, 207(2), 1122-1129.

[10]Cook, W. D., \& Seiford, L. M. (2009). Data envelopment analysis (DEA)-Thirty years on, European Journal of Operational Research, 192, 1-17.

[11]Cooper, W. W., Seiford, L. M., \& Zhu, J. (Eds.). (2011). Handbook on data envelopment analysis (Vol. 164). Springer Science \& Business Media.

[12]Du, J., Chen, Y., \& Huo, J. Z. (2015). DEA for non-homogenous parallel networks. 
Omega. 56. 122-132.

[13]Färe, R, \& Grosskopf, S. (1996). Productivity and intermediate products: A frontier approach. Economics Letters, 50, 65-70.

[14]Färe, R., \& Primont, D. (1984). Efficiency measures for multi-plant firms. Operations Research Letters, 3(5), 257-260.

[15]Gong, Y., Zhu, J., Chen, Y., \& Cook, W. D. (2018). DEA as a tool for auditing: Application to Chinese manufacturing industry with parallel network structures. Annals of Operations Research, 263(1-2), 247-269.

[16]Halkos, G. E., Tzeremes, N. G., \& Kourtzidis, S. A. (2014). A unified classification of two-stage DEA models. Surveys in operations research and management science, 19(1), 1-16.

[17]Huang, Z. M. \& Li, S. X. (2001). Co-op advertising models in a manufacturingretailing supply chain: A game theory approach, European Journal of Operational Research, 135, 527-544.

[18]Kao, C. (1998). Measuring the efficiency of forest districts with multiple working circles. Journal of the Operational Research Society, 49(6), 583-590.

[19]Kao, C. (2009a). Efficiency measurement for parallel production systems. European Journal of Operational Research, 196(3), 1107-1112.

[20]Kao, C. (2009b). Efficiency decomposition in network data envelopment analysis: A relational model. European Journal of Operational Research, 192(3), 949-962.

[21]Kao, C. (2012a). Dynamic data envelopment analysis: A relational analysis. European Journal of Operational Research, 227(2), 325-330.

[22]Kao, C. (2012b). Efficiency decomposition for parallel production systems. Journal of the Operational Research Society, 63, 64-71.

[23]Kao, C., \& Hwang, S. N. (2008). Efficiency decomposition in two-stage data envelopment analysis: An application to non-life insurance companies in Taiwan. European Journal of Operational Research, 185(1), 418-429.

[24]Kao, C., Hwang, S. H. (2010). Efficiency measurements for network systems: IT impact of firm performance, Decision Support Systems, 48, 437-446. 
[25] Khalili-Damghani, K., Tavana, M., Santos-Arteaga, F. J., \& Mohtasham, S. (2015). A dynamic multi-stage data envelopment analysis model with application to energy consumption in the cotton industry. Energy Economics. 51. 320-328.

[26]Lewis, H. F., \& Sexton, T. R. (2004). Network DEA: efficiency analysis of organizations with complex internal structure. Computers \& Operations Research, 31(9), 1365-1410.

[27]Liang, L., Cook, W. D., \& Zhu, J. (2008). DEA models for two-stage processes: Game approach and efficiency decomposition. Naval Research Logistics, 55(7), 643-653.

[28]Liang, L., Li, Z. Q., Cook, W. D., Zhu, J. (2011). DEA efficiency in two-stage networks with feedback. IIE Transaction, 43, 309-322.

[29]Li, F., Song, J., Dolgui, A., \& Liang, L. (2017). Using common weights and efficiency invariance principles for resource allocation and target setting. International Journal of Production Research, 55(17), 4982-4997.

[30]Lozano, S. (2011). Scale and cost efficiency analysis of networks of processes. Expert Systems with Applications, 38(6), 6612-6617.

[31]Lozano, S. (2015). Alternative SBM model for network DEA. Computers \& Industrial Engineering, 82, 33-40.

[32]Lozano, S. (2016). Slacks-based inefficiency approach for general networks with bad outputs: An application to the banking sector. Omega, 60, 73-84.

[33]Lozano, S., Villa, G., \& Eguía, I. (2017). Data envelopment analysis with multiple modes of functioning. Application to reconfigurable manufacturing systems. International Journal of Production Research, https://doi.org/10.1080/00207543.2017.1391418.

[34]Moreno, P., \& Lozano, S. (2014). A network DEA assessment of team efficiency in the NBA. Annals of Operations Research, 214(1), 99-124.

[35] Seiford, L. M., \& Zhu, J. (1999). Profitability and marketability of the top 55 US commercial banks. Management Science, 45(9), 1270-1288.

[36]Tone, K., \& Tsutsui, M. (2009). Network DEA: a slacks-based measure approach. 
European Journal of Operational Research, 197(1), 243-252.

[37]Wang, C. H., Gopal, R. D., \& Zionts, S. (1997). Use of data envelopment analysis in assessing information technology impact on firm performance. Annals of Operations Research, 73, 191-213.

[38]Wu, J., Zhu, Q., Chu, J., An, Q., \& Liang, L. (2016a). A DEA-based approach for allocation of emission reduction tasks. International Journal of Production Research, 54(18), 5618-5633.

[39]Wu, J., Zhu, Q., Ji, X., Chu, J., \& Liang, L. (2016b). Two-stage network processes with shared resources and resources recovered from undesirable outputs. European Journal of Operational Research, 251(1), 182-197.

[40]Xiong, B., Wu, J., An, Q., Chu, J., \& Liang, L. (2017). Resource allocation of a parallel system with interaction consideration using a DEA approach: an application to Chinese input-output table. INFOR: Information Systems and Operational Research, https://doi.org/10.1080/03155986.2017.1335046.

[41]Yu, M. M., \& Fan, C. K. (2009). Measuring the performance of multimode bus transit: A mixed structure network DEA model. Transportation Research Part E: Logistics and Transportation Review, 45(3), 501-515.

[42]Zhang, H., Patton, D., \& Kenney, M. (2013). Building global-class universities: Assessing the impact of the 985 Project, Research Policy, 42, 765-775.

[43]Zuo, K., \& Guan, J. (2017). Measuring the R\&D efficiency of regions by a parallel DEA game model. Scientometrics, 112(1), 175-194. 